\title{
Proprioceptive loss in leprous neuropathy: A study of 19 patients
}

\author{
Satish V. Khadilkar, Rajesh Benny, Prasanna S. Kasegaonkar ${ }^{1}$ \\ Department of Neurology, Grant Medical College \& Sir JJ Group of hospitals, Mumbai, ${ }^{1}$ Ashwini Hospital, Solapur, India
}

\begin{abstract}
Background: Leprosy presents commonly with mononeuritis multiplex, affecting mainly the exteroceptive sensations. Neuropathy with a significant afferent large fiber element is considered to be an uncommon manifestation of leprous neuropathy. Aims: To evaluate the clinical and neurophysiologic aspects of a subset of patients with leprous neuropathy having clinical proprioceptive loss. Settings and Design: Prospective study of patients with a diagnosis of peripheral neuropathy secondary to leprosy having proprioceptive loss. Materials and Methods: Consecutive patients seen during a two-year period (2004 and 2005) diagnosed to have leprous neuropathy with proprioceptive abnormalities on clinical examination were included. The diagnosis of leprosy was achieved by clinical features along with positive skin biopsy, split skin smears or nerve biopsy. Their clinical and electrophysiological characteristics were studied. Statistical Methods: The results were analyzed using Chi-Square test. Values less than 0.05 were considered to be statistically significant. Results and Conclusions: We observed predominance (68.42\%) of multibacillary of leprosy. Symmetrical neuropathies outnumbered mononeuritis multiplex (12:7). The pan sensory neuropathy had a mean duration of 24.32 months, but sometimes appeared early in the course of the disease. Areflexia and electrophysiological evidence of proximal affection was common, reflecting proximal spread of neuropathic process. Such patients have a higher incidence of developing deformities and ulcerations and they represent a vulnerable subset of patients with leprosy.
\end{abstract}

Key words: Electrophysiology, leprosy, mononeuritis multiplex, multibacillary, polyneuropathy, proprioception

\section{Introduction}

Leprosy is a chronic infectious disease of the skin, peripheral nerves and other tissues, resulting from interplay of immune responses of host to
Mycobacterium leprae. It was believed that leprosy predominantly involved the skin with affectation of the cutaneous nerves. With better understanding of the disease, pure neuritic forms of leprosy are increasingly being recognized. The affection of nerves is known to take various forms. The disease is known to preferentially involve only the exteroceptive sensations but proprioceptive sensory loss has been described rarely in subjects with leprosy. ${ }^{[1]}$ We undertook the present study to evaluate the clinical and neurophysiologic aspects of a subset of patients with leprous neuropathy having proprioceptive abnormalities on clinical examination.

\section{Materials and Methods}

This is a prospective study wherein we recruited consecutive patients with a diagnosis of peripheral neuropathy secondary to leprosy having proprioceptive loss, seen over the period of two years (2004 and 2005) from a tertiary referral center. Consecutive case recruitment prevented selection bias. The diagnosis of leprosy was based on clinical examination of the cutaneous and neurological systems and was confirmed by specific histopathological abnormalities either on a nerve or skin biopsy or a slit skin smear (SSS) examination. The patients were classified using Ridley and Jopling ${ }^{[2]}$ and WHO classification. ${ }^{[3]}$ All patients underwent the following steps of evaluation: a detailed history and neurological examination was done. The details of treatment were recorded. Type I lepra reaction was diagnosed when there was development of acute erythema and swelling of existing skin lesions with appearance of new ones, acute nerve pain, tenderness with fresh or worsening neural impairment with edema of hands and feet. Type II lepra reaction was identified by the presence of systemic symptoms including fever, malaise, recurrent transient cutaneous nodules, acute/ subacute nerve enlargement, and 
tenderness and in severe cases arthritis, uveitis and orchitis. ${ }^{[4]}$ Laboratory investigations [ESR, CBC, HIV, blood sugar, liver and kidney function tests] were done in all patients and ANA, ANCA and anti ds DNA were performed when feasible. All patients underwent a detailed electromyography (EMG) and nerve conduction study. Nerve conduction velocity (NCV) studies and EMG were done using standard techniques. ${ }^{[5]}$ Multiple motor nerves, i.e. median, ulnar, radial, peroneal and tibial nerves were studied bilaterally in all individuals and anti dromic sensory nerve conduction studies were performed on the median, ulnar, superficial radial, superficial peroneal and sural nerves bilaterally. Demyelinating neuropathies were diagnosed according to published criteria, ${ }^{[6,7]}$ when three of the following four criteria were met:

1. Conduction velocity of less than $90 \%$ of the lower limit of normal (LLN) (i.e., $<45 \mathrm{~m} / \mathrm{sec}$ in the arms and $36 \mathrm{~m} / \mathrm{sec}$ in the legs), if the amplitude exceeds $50 \%$ of the LLN; less than $80 \%$ of the LLN $(40 \mathrm{~m} /$ sec in the arms and $32 \mathrm{~m} / \mathrm{sec}$ in the legs), if the amplitude is less than $50 \%$ of the LLN.

2. Distal latency exceeding $115 \%$ of the upper limit of normal (ULN), if the amplitude is normal (4.8 $\mathrm{ms}$ in the median nerve and $5.9 \mathrm{~ms}$ in the legs); exceeding $125 \%$, if the amplitude is less than the LLN (5.3 $\mathrm{ms}$ in the median nerve and $6.4 \mathrm{~ms}$ in the legs).

3. Proximal or distal amplitude ratio of less than 0.7 .

\begin{tabular}{|c|c|c|}
\hline & Multibacillary & Paucibacillary \\
\hline No & 13 & 6 \\
\hline \multicolumn{3}{|l|}{ Sex } \\
\hline Male & 12 & 4 \\
\hline Female & 1 & 2 \\
\hline Mean age (Years) & 45.62 & 40.67 \\
\hline Skin lesion & $76.92 \%$ & $33.3 \%$ \\
\hline Ulcer & $30.77 \%$ & $16.67 \%$ \\
\hline Deformity & $46.15 \%$ & 0 \\
\hline Weakness & $92.31 \%$ & $66.67 \%$ \\
\hline Reaction state & $15.38 \%$ & $0 \%$ \\
\hline Thickened nerves & $100 \%$ & $83.3 \%$ \\
\hline Abnormal skin examination & $100 \%$ & $66.67 \%$ \\
\hline Areflexia & $61.54 \%$ & $66.67 \%$ \\
\hline Diagnosis & $9 \mathrm{BL}, 4 \mathrm{LL}$, & 3TT, 1BT, 2PNL \\
\hline Mean hemoglobin (gm/dL) & 11.92 & 13.13 \\
\hline Mean ESR & 29.08 & 18.83 \\
\hline EMG abnormalities & $100.00 \%$ & $100 \%$ \\
\hline F wave abnormal & $100 \%$ & $66.67 \%$ \\
\hline $\mathrm{H}$ wave abnormal & $76.92 \%$ & $33.33 \%$ \\
\hline Neuropathy type & $\begin{array}{c}8 \text { Axonal, } \\
2 \text { Demyelinating, } \\
3 \text { Mixed }\end{array}$ & $\begin{array}{c}5 \text { Axonal, } \\
1 \text { Demyelinating }\end{array}$ \\
\hline Abnormal SSS & $100 \%$ & $0 \%$ \\
\hline Abnormal nerve biopsy & 0 of 1 & 6 of 6 \\
\hline Skin biopsy & 1 of 1 & - \\
\hline Others & $\begin{array}{l}1 \text { HIV, } 1 \text { Motor tinel sign, } \\
1 \text { cord lesion }\end{array}$ & \\
\hline
\end{tabular}

4. F-wave latency exceeding $125 \%$ of the ULN (36 $\mathrm{ms}$ in median, $38 \mathrm{~ms}$ in ulnar, and $63 \mathrm{~ms}$ in tibial and peroneal nerves) or absent F-waves in one or more nerves.

Semi-quantitative EMG was performed with concentric bipolar needle electrodes on various muscles of the upper and lower limbs, including the proximal muscles like the biceps and deltoid in the upper limbs and quadriceps (vastus medialis) in the lower limbs.

\section{Statistical analysis}

The results were analyzed using various tests of significance, including Chi-Square. This statistical method was chosen as it can test the hypothesis of association of columns and rows in tabular data and can be used even with nominal data. A Chi-Square probability of .05 or less is commonly interpreted as justification for rejecting the null hypothesis that the row variable is unrelated (that is, only randomly related) to the column variable, hence we used these limits.

\section{Results}

\section{Preliminary data}

Nineteen patients fulfilled the inclusion criteria. Males (84.21\%) outnumbered females; the mean age of presentation was 44.05 years in our subjects. Using the Ridley- Jopling classification; the present study included four (21.05\%) patients with LL (lepromatous leprosy), nine $(47.37 \%)$ patients with BL (borderline lepromatous leprosy), three (15.79\%) patients with TT (tuberculoid leprosy) and one (5.26\%) patient with BT (borderline tuberculoid leprosy). There were two (10.53\%) patients with PNL (pure neuritic leprosy). Using the WHO classification, we observed six (31.58\%) patients of the PB (paucibacillary) group and 13 (68.42\%) of the MB (multibacillary) group. Table 1 shows the comparison of the paucibacillary and multibacillary groups. The mean duration of symptoms in our subjects was 24.32 months (range 1 to 108 months). All the patients were on therapy of leprosy.

\section{Clinical features}

History

Most of our subjects complained of numbness [18 (94.74\%)]. Sixteen (84.21\%) subjects complained of weakness; complaints of parasthesiae and skin lesions were reported by 13 (68.42\%) and 12 (63.16\%) patients each. Deformities (five in those with pan sensory loss and one with mononeuritis multiplex) and ulcers were present in six (31.58\%) and five $(26.32 \%)$ of our subjects respectively. All patients with deformities had multibacillary forms of leprosy (three LL, three BL). Patients with deformity had higher duration of 
symptoms (48 to 108 months) as compared to those without it (18.77 months) ( $P 0.185$ not significant). Five patients (26.32\%) had ulcer as the presenting symptom. Of these four patients belonged to the lepromatous group (three patients with LL and one patient with BL), whereas the fifth patient had tuberculoid leprosy (TT). Simultaneously studied patients of leprous neuropathy [n= 31; not included in the present study] who did not have proprioceptive loss did not have ulcerations and deformities except in one of them. Our patients had a very wide duration of symptoms, 1 to 108 months.

\section{Examination}

94.74\% of patients had thickened nerves and $89.47 \%$ had hypoasthetic skin patches. Exteroceptive and proprioceptive sensory loss was present in all the patients. Twelve patients had symmetrical neuropathies (one had BT and the rest belonged to the lepromatous group- nine BL, two LL) and the remaining seven had mononeuritis multiplex (two PNL, two TT, two LL and one BT). Weakness on examination was present in 16 (84.21\%) of the patients. Details of motor weakness have been summarized in Table 2 .

Regional areflexia [loss of deep tendon reflex in the distribution of the affected nerve] was observed in 12 (63.16\%) patients. The mean duration of symptoms in these patients with regional areflexia (31.67 months) was higher than those with retained reflexes (11.71 months) ( $P$ 0.114 not significant). Regional areflexia was observed more often in subjects with lepromatous leprosy (BL-50\%, LL- 16.67\%) and PNL (100\%).

\section{Investigations}

The mean hemoglobin level in our subjects was 12.3 $\mathrm{gm} / \mathrm{dl}$ (9.2 to $15.6 \mathrm{gm} / \mathrm{dl})$. Mean ESR was $25.84 \mathrm{~mm}$ at

\begin{tabular}{lc}
\hline & Table 2: Pattern of motor weakness \\
\hline Sr. no. & Weakness \\
1. & $4 / \mathrm{b}$ \\
2. & $1 / \mathrm{b}, 2 / \mathrm{b}, 3 / \mathrm{b}, 4 / \mathrm{b}, 5 / \mathrm{b}$ \\
3. & 0 \\
4. & $1 / \mathrm{b}, 2 / \mathrm{b}, 3 / \mathrm{b}, 4 / \mathrm{b}, 5 / \mathrm{b}$ \\
5. & $1 / \mathrm{b}, 3 / \mathrm{l}, 4 / \mathrm{b}, 5 / \mathrm{l}$ \\
6. & $1 / \mathrm{b}, 4 / \mathrm{b}, 5 / \mathrm{b}$ \\
7. & $1 / 1,3 / l, 4 / \mathrm{b}, 5 / \mathrm{b}, 6$ \\
8. & $1 / \mathrm{b}, 2 / /, 3 / \mathrm{r}, 4 / \mathrm{b}, 5 / \mathrm{b}$ \\
9. & $1 / \mathrm{l}, 4 / \mathrm{b}, 5 / \mathrm{r}$ \\
10. & $1 / \mathrm{b}, 4 / \mathrm{b}$ \\
11. & $1 / \mathrm{b}, 3 / \mathrm{r}, 4 / \mathrm{b}, 5 / \mathrm{b}$ \\
12. & $1 / /, 4 / \mathrm{b}, 5 / \mathrm{b}$ \\
13. & $1 / \mathrm{r}, 3 / \mathrm{r}, 4 / \mathrm{b}$ \\
14. & 0 \\
15. & $1 / \mathrm{r}$ \\
16. & 0 \\
17. & $1 / \mathrm{b}, 2 / /, 3 / \mathrm{b}, 4 / \mathrm{l}$ \\
18. & $4 / \mathrm{b}, 5 / \mathrm{b}$ \\
19. & $4 / \mathrm{r}, 5 / \mathrm{r}$ \\
\hline
\end{tabular}

$0=$ No weakness; $1=$ Weakness in ulnar nerve distribution; $2=$ Weakness in radial nerve distribution; $3=$ Weakness in median nerve distribution; $4=$ Weakness in peroneal nerve distribution; $5=$ Weakness in tibial nerve distribution; $6=$ Facial weakness; $\mathrm{L}=\mathrm{Left}, \mathrm{R}=$ right, $\mathrm{B}=$ bilateral the end of the first hour ( 4 to $90 \mathrm{~mm}$ ). The ANA, dsDNA and ANCA levels were done in five patients; they were negative in all. One patient was positive for the HIV virus with an ESR of $90 \mathrm{~mm}$ at the end of one hour.

\section{Electrophysiology}

The nerves commonly affected on motor nerve conduction studies (MNC) were peroneal (84.21\%), posterior tibial (78.95\%) and ulnar nerves (68.42\%); $47.37 \%$ of median nerves and only $21.05 \%$ of radial nerves were affected on MNC. Abnormality of motor studies correlated (especially $\mathrm{F}$ waves) with presence of weakness clinically ( $P=0.001$ significant).

The most commonly affected nerve on sensory nerve conduction study (SNC) was the ulnar nerve (100\%) followed by the superficial radial nerve (94.74\%). The superficial peroneal and sural nerves were abnormal in $89.47 \%$ of patients each. The median sensory nerve abnormalities were seen in $78.95 \%$ of the patients.

$68.42 \%$ of the patients had nerve conduction findings suggestive of an axonal neuropathy. Demyelinating and mixed (axonal and demyelinating) neuropathies were seen in $15.79 \%$ of our subjects each. In one patient with demyelinating neuropathy, the duration of illness was long, being 108 months.

Electrophysiological features have been summarized in Table 3.

\section{$F$ and $H$ responses}

$\mathrm{F}$ wave abnormalities were observed in $89.47 \%$ and $\mathrm{H}$ reflex abnormities in $63.16 \%$ of the patients. $\mathrm{H}$ reflex abnormalities were observed more frequently in those subjects with longer disease symptoms. Duration of symptoms in patients with $\mathrm{H}$ reflex abnormality was 30.83 months, as against those with normal $\mathrm{H}$ reflex wherein the mean duration of symptoms was 13.14 months.

Electromyographic abnormalities were most commonly seen in the distribution of the peroneal and ulnar (84.21\% each) nerves. The other nerves were affected in the following order: posterior tibial (78.95\%), median $(57.89 \%)$ and radial $(36.84 \%)$ nerves. EMG showed evidence of denervation in the distribution of 116 nerves, as compared to abnormalities of motor MNC in 96 nerves.

\section{Pathology}

Slit skin smear examination

All the patients underwent an Slit skin smear examination (SSS) examination and 13 patients were diagnosed as leprosy based on acid fast bacillus positivity. Of these nine had BL and four had LL.

\section{Skin biopsy}

In one patient with borderline lepromatous leprosy, the skin biopsy was available and histology was 


\begin{tabular}{|c|c|c|c|c|c|c|c|}
\hline Sr.no. & Active & Chronic & Motor nerves & Sensory nerves & $\mathbf{F}$ & $\mathbf{H}$ & Tyne \\
\hline 1. & $1 / r, 3 / r$ & $\begin{array}{l}1 / \mathrm{b}, 3 / \mathrm{r} \\
4 / \mathrm{b}, 5 / \mathrm{b}\end{array}$ & $\begin{array}{l}1 / \mathrm{b}, 3 / \mathrm{r} \\
4 / \mathrm{b}, 5 / \mathrm{b}\end{array}$ & $1 / \mathrm{r}, 7 / \mathrm{b}, 8 / \mathrm{b}$ & $\begin{array}{c}1 / r, 4 / b \\
5 / b\end{array}$ & $1 / b$ & 2 \\
\hline 2. & 0 & $1 / /$ & $1 / /$ & 1/I,2/I,3/l & 0 & 0 & 1 \\
\hline 3. & 0 & $4 / b$ & $4 / b$ & $1 / \mathrm{b}, 2 / \mathrm{b}$ & $1 / b, 3 / r$ & $1 / b$ & 1 \\
\hline 4. & $1 / r$ & $1 / r$ & $1 / r$ & $\begin{array}{c}1 / \mathrm{b}, 2 / \mathrm{b} \\
3 / \mathrm{b}, 7 / \mathrm{r}, 8 / \mathrm{b}\end{array}$ & $1 / r$ & 0 & 1 \\
\hline 5. & 0 & $1 / 1$ & $1 / 1$ & $\begin{array}{c}1 / b, 2 / b \\
3 / b, 7 / b, 8 / b\end{array}$ & 0 & 0 & 1 \\
\hline 6. & $1 / b$ & $\begin{array}{c}\text { 1/b,2/l, } \\
3 / \mathrm{b}, 4 / \mathrm{b}, 5 / \mathrm{b}\end{array}$ & $\begin{array}{l}2 / l, 3 / b \\
4 / b, 5 / b\end{array}$ & $\begin{array}{c}1 / \mathrm{b}, 2 / \mathrm{b}, 3 / \mathrm{b} \\
7 / \mathrm{b}, 8 / \mathrm{b}\end{array}$ & $4 / b, 5 / b$ & $1 / l$ & 3 \\
\hline 7. & $\begin{array}{c}1 / b, 2 / b \\
3 / b\end{array}$ & $\begin{array}{c}1 / \mathrm{b}, 2 / \mathrm{b} \\
3 / \mathrm{b}, 4 / \mathrm{b}, 5 / \mathrm{b}\end{array}$ & $\begin{array}{c}1 / b, 2 / b \\
3 / b, 4 / b, 5 / b\end{array}$ & $\begin{array}{c}1 / \mathrm{b}, 2 / \mathrm{b}, 3 / \mathrm{b} \\
7 / \mathrm{b}, 8 / \mathrm{b}\end{array}$ & $\begin{array}{c}1 / \mathrm{b}, 4 / \mathrm{b} \\
5 / \mathrm{b}\end{array}$ & $1 / b$ & 2 \\
\hline 8. & 0 & $1 / r, 4 / r, 5 / r$ & $1 / r, 4 / r, 5 / r$ & $\begin{array}{c}1 / \mathrm{b}, 2 / \mathrm{b}, 3 / \mathrm{r} \\
7 / \mathrm{b}, 8 / \mathrm{b}\end{array}$ & $4 / r, 5 / b$ & $1 / b$ & 1 \\
\hline 9. & $\begin{array}{c}1 / \mathrm{b}, 2 / / \\
5 / l\end{array}$ & $\begin{array}{c}1 / b, 2 / b \\
3 / b, 4 / b, 5 / b\end{array}$ & $\begin{array}{l}1 / \mathrm{b}, 2 / \mathrm{b} \\
4 / \mathrm{b}, 5 / \mathrm{b}\end{array}$ & $\begin{array}{c}1 / \mathrm{b}, 2 / \mathrm{b}, 3 / \mathrm{b} \\
7 / \mathrm{b}, 8 / \mathrm{b}\end{array}$ & $\begin{array}{c}1 / \mathrm{b}, 4 / \mathrm{b} \\
5 / \mathrm{l}\end{array}$ & 0 & 3 \\
\hline 10. & 0 & $\begin{array}{c}1 / b, 2 / b \\
3 / b, 4 / b, 5 / b\end{array}$ & $\begin{array}{l}1 / \mathrm{b}, 3 / \mathrm{b} \\
4 / \mathrm{b}, 5 / \mathrm{b}\end{array}$ & $\begin{array}{c}1 / \mathrm{b}, 2 / \mathrm{b}, 3 / \mathrm{b} \\
7 / \mathrm{b}, 8 / \mathrm{b}\end{array}$ & $1 / b, 3 / b$ & 0 & 1 \\
\hline 11. & 0 & $4 / b, 5 / b$ & $4 / \mathrm{b}, 5 / \mathrm{b}$ & $\begin{array}{l}1 / /, 2 / \mathrm{b} \\
7 / \mathrm{b}, 8 / \mathrm{b}\end{array}$ & $4 / b, 5 / b$ & $1 / b$ & 1 \\
\hline 12. & 0 & $1 / b, 4 / b, 5 / b$ & $4 / /, 5 / b$ & $\begin{array}{c}\text { 1/b,2/b,3/l, } \\
7 / \mathrm{b}, 8 / \mathrm{b}\end{array}$ & $4 / b$ & $1 / 1$ & 1 \\
\hline 13. & 0 & $\begin{array}{c}\text { 1/l,3/l, } \\
4 / \mathrm{b}, 5 / \mathrm{b}, 6\end{array}$ & $\begin{array}{c}1 / b, 3 / l \\
, 4 / b, 5 / b\end{array}$ & $\begin{array}{c}1 / \mathrm{b}, 2 / \mathrm{b}, 3 / \mathrm{b} \\
7 / \mathrm{b}, 8 / \mathrm{b}\end{array}$ & $\begin{array}{l}\text { 1/b,3/l, } \\
4 / b, 5 / b\end{array}$ & 0 & 1 \\
\hline 14. & 0 & $\begin{array}{c}\text { 1/b,2/l, } \\
3 / \mathrm{r}, 4 / \mathrm{b}, 5 / \mathrm{b}\end{array}$ & $\begin{array}{c}1 / l, 2 / r, 3 / r \\
4 / b, 5 / b\end{array}$ & $\begin{array}{c}1 / \mathrm{b}, 2 / \mathrm{b}, 3 / \mathrm{b} \\
7 / \mathrm{b}, 8 / \mathrm{b}\end{array}$ & $\begin{array}{l}1 / b, 3 / b \\
4 / b, 5 / b\end{array}$ & $1 / b$ & 1 \\
\hline 15. & 0 & $\begin{array}{l}1 / \mathrm{b}, 3 / \mathrm{r} \\
4 / \mathrm{b}, 5 / \mathrm{r}\end{array}$ & $1 / \mathrm{l}, 4 / \mathrm{b}, 5 / \mathrm{r}$ & $\begin{array}{c}1 / \mathrm{b}, 2 / \mathrm{l}, 3 / \mathrm{r} \\
7 / \mathrm{b}, 8 / \mathrm{b}\end{array}$ & $\begin{array}{c}1 / \mathrm{b}, 4 / \mathrm{b} \\
5 / \mathrm{b}\end{array}$ & $1 / b$ & 3 \\
\hline 16. & 0 & $\begin{array}{c}1 / \mathrm{b}, 2 / \mathrm{b} \\
3 / \mathrm{b}, 4 / \mathrm{b}, 5 / \mathrm{b}\end{array}$ & $3 / b, 4 / b, 5 / b$ & $\begin{array}{c}1 / \mathrm{b}, 2 / \mathrm{b}, 3 / \mathrm{b} \\
7 / \mathrm{b}, 8 / \mathrm{b}\end{array}$ & $4 / b, 5 / b$ & $1 / b$ & 1 \\
\hline 17. & 0 & $\begin{array}{c}1 / b, 2 / b \\
3 / b, 4 / b, 5 / b\end{array}$ & $\begin{array}{l}1 / \mathrm{b}, 3 / \mathrm{l} \\
4 / \mathrm{b}, 5 / \mathrm{b}\end{array}$ & $\begin{array}{c}1 / \mathrm{b}, 2 / \mathrm{b}, 3 / \mathrm{b} \\
7 / \mathrm{b}, 8 / \mathrm{b}\end{array}$ & $\begin{array}{l}1 / \mathrm{b}, 3 / \mathrm{r} \\
4 / \mathrm{b}, 5 / \mathrm{b}\end{array}$ & $1 / b$ & 1 \\
\hline 18. & 0 & $4 / r, 5 / r$ & $4 / r, 5 / r$ & $\begin{array}{c}\text { 1/r,2/l, } \\
7 / \mathrm{b}, 8 / \mathrm{b}\end{array}$ & $\begin{array}{c}1 / l, 4 / r \\
5 / r\end{array}$ & 0 & 1 \\
\hline 19. & 0 & $\begin{array}{l}1 / b, 3 / b \\
4 / b, 5 / b\end{array}$ & $\begin{array}{l}1 / b, 3 / b \\
4 / b, 5 / b\end{array}$ & $\begin{array}{c}1 / \mathrm{b}, 2 / \mathrm{b} \\
3 / \mathrm{l}, 7 / \mathrm{b}, 8 / \mathrm{b}\end{array}$ & $\begin{array}{l}1 / b, 3 / b \\
4 / b, 5 / b\end{array}$ & $1 / r$ & 2 \\
\hline
\end{tabular}

Active: Active denervation in distribution of nerve. $0=$ No denervation, $1=$ Denervation in ulnar nerve distribution, $2=$ Denervation in radial nerve distribution, $3=$ Denervation in median nerve distribution, $4=$ Denervation in peroneal nerve distribution, $5=$ Denervation in tibial nerve distribution $/ r=$ Right side, $/ /=$ Left side, $/ \mathrm{b}=\mathrm{Bilateral}$; Chronic: Chronic denervation and/or reinnervation in distribution of nerve. $0=$ No denervation, $1=$ Denervation in ulnar nerve distribution, $2=$ Denervation in radial nerve distribution, $3=$ Denervation in median nerve distribution, $4=$ Denervation in peroneal nerve distribution, $5=$ Denervation in tibial nerve distribution $/ \mathrm{r}=\mathrm{Right}$ side, $/ \mathrm{l}=\mathrm{Left}$ side, $/ \mathrm{b}=$ Bilateral; Motor nerve: Electrophysiologically (on motor nerve conduction) abnormal motor nerve.1=Ulnar nerve, $2=$ Radial nerve, $3=$ Median nerve, 4= Peroneal nerve, $5=$ Tibial nerve, $0=$ No abnormality. / $r=$ Right side, /l=Left side, / $b=$ Bilateral; Sensory nerve: Electrophysiologically (on sensory nerve conduction)

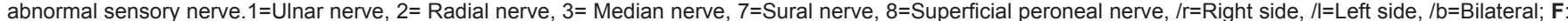
F wave abnormalities on nerve conduction study (NCS). 1=Ulnar nerve, $2=$ Radial nerve, $3=$ Median nerve, $4=$ Peroneal nerve, $5=$ Tibial nerve, $0=$ No abnormality. $/$ r=Right side, /l=Left side, /b=Bilateral; H: H reflex abnormality on NCS of lower limb. 0= Normal, 1= Abnormal. /r=Right side, /l=Left side, /b=Bilateral; Type: Type of neuropathy on NCS: $1=$ Predominantly axonal neuropathy, $2=$ Predominantly demyelinating neuropathy, $3=$ Mixed demyelinating and axonal neuropathy.

consistent with the diagnosis.

\section{Nerve biopsy}

Nerve biopsy was obtained in seven patients and showed evidence of leprosy in six patients. The biopsy was normal in one patient (14.29\%). This patient had positive skin pathology. Table 4 summarizes the pathological features.

\section{Discussion}

\section{Preliminary data}

The mean age of presentation [44.05 years] and the male predominance [84.21\%] seen in the present study match with most studies, ${ }^{[8]}$ except those in some areas of Africa, where females are more commonly affected. ${ }^{[8]}$ The mean duration of symptoms in our patients was long, being 24.32 months and the prevalence of various types of leprosy seen in the present study is in accordance with published data. ${ }^{[9]}$

\section{Clinical features of neuropathies}

On clinical evaluation, symmetrical neuropathies outnumbered mononeuritis multiplex [12/7]. The patients with symmetrical neuropathies belonged to the lepromatous group which is in accordance with published literature; those with severe and widespread involvement have a glove and stocking pattern of sensory loss. ${ }^{[4]}$ These patients had higher association of deformities and ulcerations and SSS was positive in most of them (11/12). Two patients were in reaction states. As against this, the group with the mononeuritis multiplex pattern had fewer deformities, the SSS was 


\begin{tabular}{|c|c|c|c|c|}
\hline \multicolumn{5}{|c|}{ Table 4: Pathological features } \\
\hline Sr. no. & Diagnosis & SSS & Nerve biopsy & Others \\
\hline 1. & LL & Positive & - & HIV positive \\
\hline 2. & LL & Positive & - & - \\
\hline 3. & LL & Positive & - & $\begin{array}{l}\text { Motor } \\
\text { tinel sign }\end{array}$ \\
\hline 4. & LL & Positive & - & - \\
\hline 5. & $\mathrm{BL}$ & Positive & - & - \\
\hline 6. & $\mathrm{BL}$ & Positive & - & - \\
\hline 7. & $\mathrm{BL}$ & Positive & - & - \\
\hline 8. & $\mathrm{BL}$ & Positive & - & - \\
\hline 9. & $\mathrm{BL}$ & Positive & - & $\begin{array}{c}\text { Skin biopsy } \\
\text {-BLH }\end{array}$ \\
\hline 10. & $\mathrm{BL}$ & Positive & - & - \\
\hline 11. & $\mathrm{BL}$ & Positive & - & - \\
\hline 12. & $\mathrm{BL}$ & Positive & - & - \\
\hline 13. & $\mathrm{BL}$ & Positive & Negative & - \\
\hline 14. & BT & Negative & $\begin{array}{c}\text { s/o } \\
\begin{array}{c}\text { BorderlineTuberculoid } \\
\text { leprosy }\end{array}\end{array}$ & - \\
\hline 15. & TT & Negative & $\begin{array}{l}\text { s/o tuberculoid } \\
\text { Leprosy }\end{array}$ & - \\
\hline 16. & TT & Negative & $\begin{array}{l}\text { s/o tuberculoid } \\
\text { Leprosy }\end{array}$ & - \\
\hline 17. & TT & Negative & $\begin{array}{l}\text { s/o tuberculoid } \\
\text { Leprosy }\end{array}$ & - \\
\hline 18. & PNL & Negative & $\begin{array}{l}\text { s/o Leprous } \\
\text { neuropathy }\end{array}$ & - \\
\hline 19. & PNL & Negative & $\begin{array}{l}\text { s/o Leprous } \\
\text { neuropathy }\end{array}$ & - \\
\hline
\end{tabular}

less often positive (2/7) and none of these patients were in reaction states.

Studying all 19 patients as a whole, it was seen that these patients with proprioceptive loss tended to be in the multibacillary category [68.42\%], suggesting that increased bacillary load results in pan sensory affection of the peripheral nervous system. The proprioceptive loss related strongly with the development of ulcers and deformities. Simultaneously studied patients of leprous neuropathy $[n=31]$ who did not have proprioceptive loss did not have ulcerations and deformities except in one of them. Patients with proprioceptive loss have increased chances of complications related to the increased presence of deformities; having a bearing on the management of such patients.

Proprioceptive loss has been reported only occasionally in leprous neuropathy. Van Barkel et al. found joint position sense abnormalities in only seven of 303 multibacillary patients with leprous neuropathy. ${ }^{[10]}$ Pandya et al. ${ }^{[1]}$ reported six such patients who presented with progressive sensory ataxia and had pseudo-athetosis of fingers and generalized areflexia. In one of their patients, histopathology of the lumbar sensory ganglion revealed extensive neuron loss and degeneration with reactive proliferation of capsular cells; an inflammatory focus of lymphocytes. No bacilli were detected in the specimen. Authors suggested that proprioceptive loss in those patients was a result of 'leprous ganglionitis'. Misra et al. ${ }^{[11]}$ have reported a single patient with BTH in Type 1 reaction, who clinically had pseudo-athetosis. One patient in the present study, reported previously, was demonstrated to have not only ganglionitis, but more proximal involvement in the form of a spinal cord granuloma on Gadolinium-enhanced magnetic resonance imaging scan of the cervical spine. His electrophysiological studies demonstrated proximal involvement. ${ }^{[12]}$

Studying the proprioceptive loss in time frame, it was clear that even though the mean duration of the group was long; the range was very wide; being one to 108 months. The proprioceptive sensory loss did not have significant relation to duration of symptoms. This lack of correlation in time frame is intriguing as severity of neuropathy logically would increase with the duration of disease. Immune factors of host parasite reaction may be relevant in the development of the pattern of neuropathy. It is tempting to postulate that lepra reactions may have been responsible for the severe nerve damage. Even though evidence of lepra reactions was present in only two patients, burnt out reactions in the past may have eluded documentation but could be responsible. This aspect needs further exploration, as immunosuppressive therapy at an early stage may become important in preventing the immune-related nerve damage and its sequel.

\section{Weakness and regional areflexia}

In the present study, 16 (84.21\%) patients had weakness on examination, pointing to affectation of large myelinated fibers going hand in hand with the proprioceptive loss. The 12 patients with regional areflexia had a longer duration of symptoms as compared to those without areflexia [.67 months vs. .71 months] which has been previously noted..$^{[13]}$ The areflexia has been believed to suggest proximal extension of the neuropathy and is seen more often with reaction states. ${ }^{[4]}$ In the present study, two patients were seen in reaction state and one of them had areflexia.

\section{Electrodiagnosis}

The sensory and motor nerve conduction studies showed abnormalities suggesting axonal neuropathy. We had three subjects with a demyelinating neuropathy; and in one of them, the duration of illness was long, being 108 months. This patient is unusual as demyelinating neuropathies are seen early in the disease process. ${ }^{[14]}$ Comparing the EMG and the MNC findings, EMG was found to be more sensitive for diagnosing motor affection in leprosy.

\section{$F$ wave and $H$ reflex study}

$\mathrm{F}$ wave and $\mathrm{H}$ reflex abnormalities were common in our patients. In view of the distal segment involvement evidenced by reduced compound muscle action potential and sensory nerve action potential, the interpretation of abnormalities in $\mathrm{F}$ and $\mathrm{H}$ reflex is speculative but 
may suggest additional proximal affection of the neural pathway in patients of leprosy having proprioceptive loss. $\mathrm{H}$ reflex abnormalities were associated with a higher mean duration of symptoms.

\section{Nerve biopsy}

Histopathological examination of a cutaneous nerve is required to diagnose primary neuritic leprosy. It could also be obtained in cutaneous nerves under the skin patch, if skin biopsy or smear is negative. Pannikar et $a .^{[15]}$ studied radial cutaneous nerve biopsy in patients of leprosy and found negative results in $35 \%$ of patients. In the present study, nerve biopsy was obtained in seven patients and showed evidence of Hansen's disease in six patients. The biopsy was normal in one patient (14.29\%). The incidence of negative results on nerve biopsy was less as compared to that found by Pannikar et al. ${ }^{[15]}$ It could be related to the patchy nature of the infectious process.

\section{Conclusions}

This small series studies the clinical and electrophysiological characterization of subjects with leprous neuropathy having proprioceptive sensory loss. These patients appear to form a distinct subtype of leprous neuropathy. Such patients have multibacillary forms of leprosy; develop a pan sensory neuropathy, being often symmetrical and sometimes early in the course of the disease. Areflexia and electrophysiological evidence of proximal affectation is common, reflecting proximal spread of neuropathic process. The extent and the severity of the process do not seem to link to the duration of disease; but to an extent, correlate with the bacterial load. As these patients have higher chances of developing deformities and ulcerations, they represent a vulnerable subset of patients with leprosy.

\section{References}

1. Pandya SS, Bhakti WS. Severe pan-sensory neuropathy in leprosy. Int J Lepr Other Mycobact Dis 1994;62:24-31.

2. Ridley DS, Jopling WH. Classification of leprosy according to immunity: A five group system. Int J Lepr Other Mycobact Dis 1966;34:255-73.

3. Shepard CC, Walker LL, Van Landingham RM, Ye SZ. Sensitisation or tolerance to Mycobacterium leprae antigen by route of infection. Infect Immun 1982;38:673-80.

4. Pandya SS, Shetty VP. The neuropathy of leprosy. In: Wadia NH, editor. Neurological Practice- an Indian Perspective. 1st ed. Elsevier Publications; p. 167-95.

5. Aminoff MJ. In: Electromyography in clinical practice. 3rd Ed. New York: Churchill Livingstone; 1998.

6. Mygland A, Monstad P. Chronic acquired demyelinating symmetric polyneuropathy classified by pattern of weakness. Arch Neurol 2003;60:260-4.

7. Albers JW, Kelly JJ Jr. Acquired inflammatory demyelinating polyneuropathies: Clinical and electrophysiological features. Muscle Nerve 1989;12:435-51

8. Soysal A, Atay T, Ozu T, Arpaci B. Electrophysiological evaluation of peripheral and autonomic involvement in leprosy. Can J Neurol Sci 2004;31:357-62.

9. Samant G, Shetty VP, Uplekar MW, Antia NH. Clinical and electrophysiological evaluation of nerve function impairment following cessation of multidrug therapy in leprosy. Lepr Rev 1999;70:10-20.

10. Van Brakel WH, Nicholls PG, Das L, Barkataki P, Suneetha SK, Jadhav RS, et al. The INFIR Cohort Study: Investigating prediction, detection and pathogenesis of neuropathy and reactions in leprosy, Methods and baseline results of a cohort of multibacillary leprosy patients in north India. Lepr Rev 2005;76:14-34.

11. Misra UK, Kalita J, Mahadevan A, Shankar SK. Pseudoathetosis in a patient with leprosy. Mov Disord 2003;18:598-601.

12. Khadilkar SV, Kasegaonkar PS, Ursekar M. Spinal cord involvement and ganglionitis in leprosy. Neurol India 2007;55:427-8.

13. Sena PG. Electromyographic and neurological aspects of leprosy: Study of 100 cases. Arq Neuropsiquiatr 1976;34:1-17.

14. Shetty VP, Mehta LN, Antia NH, Irani PF. Teased fibre study of early nerve lesions in leprosy and in contacts, with electrophysiological correlates. J Neurol Neurosurg Psychiatry 1977;40:708-11.

15. Pannikar VK, Arunthathi S, Chako CJ, Fritschi EP. A clinico-pathological study of primary neuritic leprosy. Lepr India 1983;55:212-21.

Accepted on 07-06-2008

Source of Support: Nil, Conflict of Interest: None declared. 